\title{
Ammonium tetrathiomolybdate enhances the antitumor effect of cisplatin via the suppression of ATPase copper transporting beta in head and neck squamous cell carcinoma
}

\author{
SHOJI RYUMON $^{1}$, TATSUO OKUI ${ }^{1}$, YUKI KUNISADA ${ }^{1}$, KOJI KISHIMOTO $^{1}$, \\ TSUYOSHI SHIMO ${ }^{2}$, KAZUAKI HASEGAWA ${ }^{1}$, SOICHIRO IBARAGI ${ }^{1}$, KENTARO AKIYAMA $^{3}$, \\ NGUYEN THI THU HA ${ }^{3}$, NUR MOHAMMAD MONSUR HASSAN ${ }^{4}$ and AKIRA SASAKI ${ }^{1}$
}

\begin{abstract}
${ }^{1}$ Department of Oral and Maxillofacial Surgery, Okayama University Graduate School of Medicine, Dentistry, and Pharmaceutical Sciences, Okayama 700-8525; ${ }^{2}$ Division of Reconstructive Surgery for Oral and Maxillofacial Region, Department of Human Biology and Pathophysiology, School of Dentistry, Health Sciences University of Hokkaido, Hokkaido 061-0293; ${ }^{3}$ Department of Oral Rehabilitation and Regenerative Medicine,

Okayama University Graduate School of Medicine, Dentistry, and Pharmaceutical Sciences, Okayama 700-8525, Japan;

${ }^{4}$ School of Dentistry and Health Sciences, Charles Sturt University, Orange, NSW 2800, Australia
\end{abstract}

Received May 17, 2019; Accepted September 26, 2019

DOI: $10.3892 /$ or.2019.7367

\begin{abstract}
Platinum-based antitumor agents have been widely used to treat head and neck squamous cell carcinoma (HNSCC) and numerous other malignancies. Cisplatin is the most frequently used platinum-based antitumor agent, however drug resistance and numerous undesirable side effects limit its clinical efficacy for cancer patients. Cancer cells discharge cisplatin into the extracellular space via copper transporters such as ATPase copper transporting beta (ATP7B) in order to escape from cisplatin-induced cell death. In the present study, it was demonstrated for the first time that the copper chelator ammonium tetrathiomolybdate (TM) has several promising effects on cisplatin and HNSCC. First, TM suppressed the ATP7B expression in HNSCC cell lines in vitro, thereby enhancing the accumulation and apoptotic effect of cisplatin in the cancer cells. Next, it was revealed that TM enhanced the antitumor effect of cisplatin in HNSCC cell tumor progression in a mouse model of bone invasion, which is important since HNSCC cells frequently invade to facial bone. Finally, it was demonstrated that TM was able to overcome the cisplatin resistance of a human cancer cell line, A431, via ATP7B depression in vitro.
\end{abstract}

Correspondence to: Tatsuo Okui, Department of Oral and Maxillofacial Surgery, Okayama University Graduate School of Medicine, Dentistry, and Pharmaceutical Sciences, 2-5-1 Shikata-cho, Kita-ku, Okayama 700-8525, Japan

E-mail: pphz1rke@okayama-u.ac.jp

Key words: copper transporter, head and neck squamous cell carcinoma, ATP7B, cisplatin

\section{Introduction}

Head and neck squamous cell carcinoma (HNSCC) is a common malignant tumor $(1,2)$. Despite advances in the early detection, diagnosis, and management of HNSCC, the long-term survival rate of HNSCC patients has improved only marginally over the past decades, and more effective strategies for the treatment of HNSCC are thus required (3). Although immunotherapy with anti-programmed cell death protein 1 (anti-PD-1) and therapy with anti-epidermal growth factor receptor (anti-EGFR) were recently approved in many countries for the treatment of HNSCC patients, cisplatin is still the most widely used antitumor drug for HNSCC (4-6).

First synthesized in 1844 (7), cisplatin, or cis-diamminedichloroplatinum (II), is a metallic (platinum) coordination compound with a square planar molecular geometry. Cisplatin is activated via the replacement of a chloride ligand with $\mathrm{H}_{2} \mathrm{O}$ in the cancer cell cytoplasm. Activated cisplatin binds to the N7 atom of guanines in DNA, which in turn generates intra-strand DNA crosslinks (ICLs) (8). ICLs are cytotoxic lesions with a covalent linkage between opposite strands of double-stranded DNA. ICLs lead to defects of vital DNA metabolic processes such as transcription and DNA replication in cancer cells, resulting in cancer cell death (9). HNSCC patients usually exhibit a good response to cisplatin chemotherapy however later relapse, since the development of cisplatin resistance markedly reduces the clinical effectiveness of this agent (10). Some research indicates that cisplatin resistance can result from variations of genetic and protein expression at the cellular level $(11,12)$. Another mechanism of cisplatin resistance consists of reducing the cellular accumulation of cisplatin by increasing its efflux and suppressing its influx (13). It was revealed that the copper transporter ATP7B (ATPase copper transporting beta) is linked to cisplatin efflux from cancer cells (14). Copper transporter expression 
is closely linked to the serum copper concentration (15). The copper chelator ammonium tetrathiomolybdate (TM) may be effective for the treatment of copper metabolism disorder and Wilson's disease (16). We previously demonstrated that copper chelators have a bone-protective effect against bone-invasive HNSCC cells (17), however, the potential influence of TM on the accumulation of cisplatin in cancer cells in HNSCC is not clear. The present findings provide the first evidence that the copper chelator TM enhances the antitumor effect of cisplatin via ATP7B suppression in an HNSCC mouse model.

\section{Materials and methods}

Reagents. SLC31A1/CTR1 antibody (anti-rabbit, polyclonal; cat. no. GTX48534) was purchased from GeneTex. ATP7A (anti-rabbit, polyclonal; ID product code ab125137) was purchased from Abcam. ATP7B (anti-rabbit, polyclonal; cat. no. NB100-360) was purchased from Novus Biologicals. Cleaved caspase-3 (Asp175) (5A1E) (anti-rabbit, monoclonal; product no. 9664), Ki-67 (D2H10) (anti-rabbit, monoclonal; product no. 9027), and horseradish peroxidase (HRP)-conjugated IgG antibody (goat anti-rabbit, monoclonal; product no. 7074) were purchased from Cell Signaling Technology, Inc.

Cell lines and culture conditions. The human oral squamous cell carcinoma lines HSC-2 (\#JCRB0622), HSC-3 (\#JCRB0623), and HSC-4 (\#JCRB0624) and the human skin squamous cell carcinoma line A431 (\#JCRB004) were obtained from the Human Science Research Resources Bank (Osaka, Japan). All cell lines were cultured in Dulbecco's modified Eagle's medium (DMEM) (Thermo Fisher Scientific, Inc.) supplemented with $10 \%$ heat-inactivated fetal bovine serum (FBS) and $1 \%$ penicillin-streptomycin. All cell lines were cultured in an atmosphere of $10 \% \mathrm{CO}_{2}$ at $37^{\circ} \mathrm{C}$. The cis-dichloro-diamine-platinum (CDDP)-resistant subline A431/CDDP-R was derived from the previously established human epidermoid carcinoma cell line A431 (18). The subline A431/CDDP-R, which was established by mutagenic induction, was revealed to have 2.7 times more resistance to CDDP than the parent cell line A431 based on the half maximal inhibitory concentration $\left(\mathrm{IC}_{50}\right)(19)$.

Tissue microarray analysis. The expression of ATP7B was analyzed in head and neck cancer tissue and in a normal tissue microarray (\#OR601c; US Biomax). The antigen was activated by cooking in a citric acid solution. For the immunohistochemical analysis, the specimens were incubated with anti-ATP7B antibody $(1: 250)$ overnight at $4^{\circ} \mathrm{C}$. The slides were then treated with a streptavidin-biotin complex (EnVision System Labeled Polymer, HRP; Dako; Agilent Technologies, Inc.) for $60 \mathrm{~min}$ at a dilution of 1:100. The immunoreaction was visualized with the use of a DAB substrate-chromogen solution (Dako Cytomation Liquid DAB Substrate Chromogen System; Dako; Agilent Technologies, Inc.). The cells were counted using a light microscope and evaluated.

Western blot analysis. Protein determination performed by Bradford assay. A total of $15 \mu \mathrm{g}$ protein were mixed with $4 \mathrm{X}$ Laemmli sample buffer (Bio-Rad Laboratories, Inc.) and boiled at $95^{\circ} \mathrm{C}$ for $5 \mathrm{~min}$. The samples were electrophoresed in $4-12 \%$ sodium dodecyl sulfate-polyacrylamide gel electrophoresis (SDS-PAGE) gels, and the proteins were transferred onto polyvinylidene difluoride (PVDF) membranes (Bio-Rad Laboratories, Inc.) and blocking with 5\% skim milk for $1 \mathrm{~h}$. The membranes were incubated with primary $\left(4^{\circ} \mathrm{C}\right.$, for $\left.24 \mathrm{~h}\right)$ and secondary (room temperature, for $1 \mathrm{~h}$ ) antibodies according to the ECL chemiluminescence protocol (product no. RPN2109; Amersham Biosciences; GE Healthcare Life Sciences) to detect secondary antibody binding. Antibodies against ATP7A $(1: 1,000)$, ATP7B $(1: 1,000)$, CTR $1(1: 1,000)$, caspase-3 $(1: 1,000)$, cleaved caspase-3 $(1: 1,000), \beta$-actin $(1: 10,000)$ and GAPDH $(2,000)$ were used as primary antibodies. HRP-conjugated anti-rabbit antibody $(1: 2,000)$ was used as the secondary antibody. A ChemiDoc MP system (Bio-Rad Laboratories, Inc.) was used for the analysis of western blots.

Flow cytometric analysis. HSC-3 cells were treated with cisplatin with or without TM for $24 \mathrm{~h}$. Cells were washed and fixed, then incubated with Annexin V-FITC and PE (cat. no. 88-8005-72, cat. no. 00-6990; eBioscience; Thermo Fisher Scientific, Inc.). After staining, the cells were washed, suspended in the FACS staining buffer, and analyzed on a FACS Aria III flow cytometer using FlowJo. Ver.10 (both from BD Biosciences).

Real-time PCR analysis. Total RNA from cells was extracted using RNA easy Mini kit (Qiagen Sciences, Inc.). cDNA synthesis was performed with $1 \mu \mathrm{g}$ of total RNA using PrimeScript (Takara Bio, Inc.). Real time PCR analysis was carried out with iQ SYBR Green Mix using the CFX Connect Real-Time PCR Detection System (Bio-Rad Laboratories, Inc.). Detection was carried under following cycle conditions. Initial denaturation at $95^{\circ} \mathrm{C}$ for $30 \mathrm{sec}$, followed by 41 cycles of $95^{\circ} \mathrm{C}$ for $10 \mathrm{sec}$ and $60^{\circ} \mathrm{C}$ for $35 \mathrm{sec}$.

The primer sequence for ATP7B was forward, 5-GCC AGCATTGCAGAAGGAAAG-3 and reverse, 5-TGATAA GTGATGACGGCCTCT-3; and for $\beta$-actin, forward, 5-GAA AATCTGGCACCACACCTT-3 and reverse, 5-TTGAAGGTA GTTTCGTGGAT-3.

The relative fold change values were evaluated by normalization to $\beta$-actin expression via the $2^{-\Delta \Delta \mathrm{Cq}}$ method (20).

Cell proliferation assay. The HSC-2 and HSC-3 cells were each plated in six-well plates at a density of $1 \times 10^{5}$ cells/well. Two 6-well plates, one for each cell line, were used for each of the four groups: A control, cisplatin-treated, TM-treated, and cisplatin+TM-treated group. After $72 \mathrm{~h}$, the cells were counted using a TC20 automated cell counter (Bio-Rad Laboratories, Inc.).

Immunocytochemical analysis. HSC-3 cells were plated on culture slides (BD Falcon; BD Biosciences) at a density of $1 \times 10^{3}$ cells/well. After cisplatin or TM treatment, the number of apoptotic cells was assessed by the DeadEnd ${ }^{\mathrm{TM}}$ Fluorometric TUNEL System (Promega, Corporation).

Cisplatin concentration assay. The cisplatin concentrations in the cell suspensions were measured by a cisplatin assay kit (MicroMolar Cisplatin Assay Kit; ProFoldin). The samples, buffer, and chelate color solution were mixed and incubated for 
A a

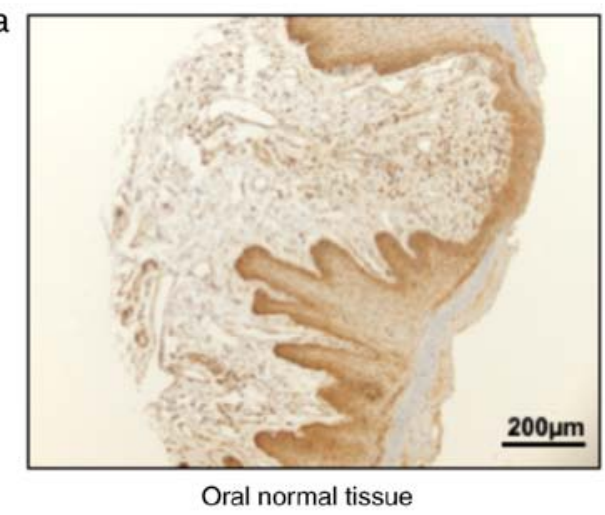

B
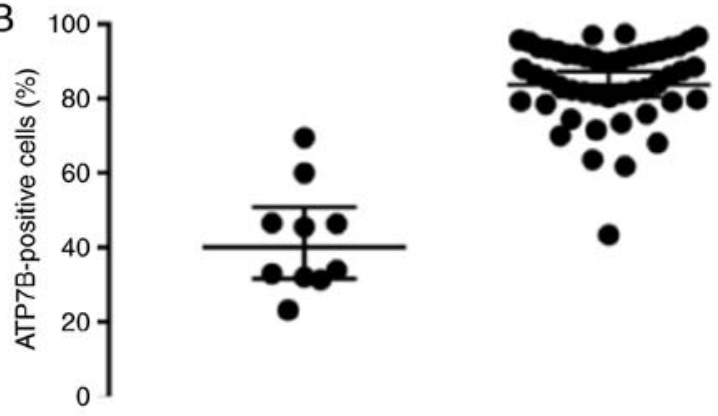

b

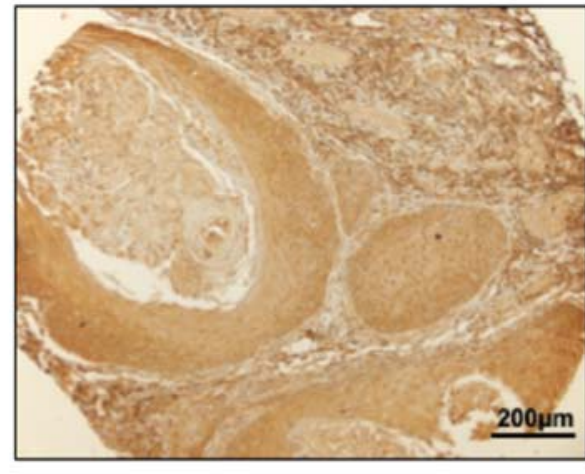

HNSCC

C

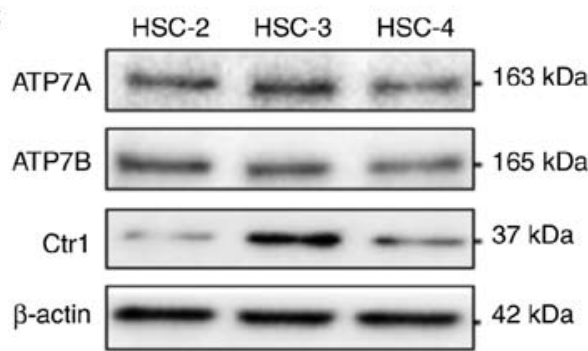

Oral normal tissue

HNSCC

Figure 1. Expression of ATP7B in head and neck normal tissues, head and neck cancers, and human oral squamous cell lines. (A) Immunohistochemistry results of ATP7B expression in (a) head and neck normal tissue and (b) HNC. (B) Scatterplot of the ATP7B-positive areas in the head and neck normal tissues $(n=11)$ and HNSCC $(n=70)$. Error bars: Mean \pm SD. There was a significantly increased expression of ATP7B in the HNSCC samples $(P<0.0001)$. $(C)$ The expression of ATP7B in the human oral squamous cell lines (HSC-2, -3, -4) analyzed by western blotting. HNC, head and neck cancer; HNSCC, head and neck squamous cell carcinoma; ATP7B, ATPase copper transporting beta.

$60 \mathrm{~min}$ at $65^{\circ} \mathrm{C}$. The absorbance was then read at a wavelength of $535 \mathrm{~nm}$ using a microplate reader (SH-1000; Hitachi).

Animal experiments. A mouse model of bone invasion by human oral squamous cell carcinoma was established in 5 -week-old male BALB/c nude mice ( $n=6$ per group; $n=24$ total; mean body weight, $19.5 \mathrm{~g}$; Charles River Laboratories) by i.p. inoculation of $1 \times 10^{5} \mathrm{HSC}-3$ cells into the bone marrow space of the right tibial metaphysis under general anesthesia with $0.4 \mathrm{mg} / \mathrm{kg}$ of medetomidine, $4.0 \mathrm{mg} / \mathrm{kg}$ of midazolam and $5.0 \mathrm{mg} / \mathrm{kg}$ of butorphanol Mice were maintained in SPF cages. Body condition scoring was applied and body weight was monitored daily. At 7 days after the tumor cell inoculation, the mice were divided into four groups (control, cisplatin-treated, TM-treated, and cisplatin+TM-treated). The cisplatin group was treated with a single intraperitoneal injection of $100 \mu \mathrm{l}$ of cisplatin $(5 \mathrm{mg} / \mathrm{kg})$. The TM group was orally administered $200 \mu \mathrm{l}$ of a solution containing TM $(1 \mathrm{mg})$ in phosphate-buffered saline (PBS) 5x/week for 2 weeks. The cisplatin+TM-treated group was treated with both agents at the doses used in the cisplatin group and TM group. At the end of the experimental period (day 35), the mice were sacrificed with cervical dislocation by formal trained researcher under anesthesia with $0.4 \mathrm{mg} / \mathrm{kg}$ of medetomidine, $4.0 \mathrm{mg} / \mathrm{kg}$ of midazolam and $5.0 \mathrm{mg} / \mathrm{kg}$ of butorphanol (i.p) and the right tibias of the nude mice that had been injected with the cancer cells were excised and then fixed in $4 \%$ paraformaldehyde phosphate buffer solution. There were no differences in body weight in the control (24.9 g), cisplatin (24.1 g), TM (24.5 g) and dual-treated group (23.9 g) at the end of the experiment. The criteria of humane endpoints for euthanasia was loss of $>20$ percent of body weight compared to the age-matched controls. Death of the animal was verified by cessation of cardiovascular and respiratory movements. All of the animal experimental protocols were approved by the Ethics Review Committee for Animal Experimentation of the Okayama University Graduate School of Medicine and Dentistry (approval no. OKU-2018663).

In vivo radiography and assessment of osteolytic lesion areas. Osteolytic bone destruction in the mice was assessed on radiographs. The bones were placed against films $(22 \times 27 \mathrm{~cm}$; Fuji Industrial Film FR; Fuji Photo Film) and exposed to soft X-rays at $35 \mathrm{kV}$ for $15 \mathrm{sec}$ with the use of a Sofron apparatus (Sofron). The radiolucent bone lesions were observed microscopically (IX81; Olympus Corporation), and the areas were quantified with Lumina Vision/OL image software (Mitani Corporation). A micro-CT image was obtained with a SKYSCAN scanner (Bruker Japan).

Immunohistochemical analysis. Each tibial bone was fixed in $10 \%$ formalin at room temperature for $48 \mathrm{~h}$, decalcified, and then embedded in paraffin. Serial sections were then prepared (5 $\mu \mathrm{m}$-thick). The specimens were incubated with ATP7B (1:250), Ki-67 (1:250) or IL-6 (1:100) antibodies overnight at $4{ }^{\circ} \mathrm{C}$, followed by Alexa Fluor 488 anti-rabbit IgG 

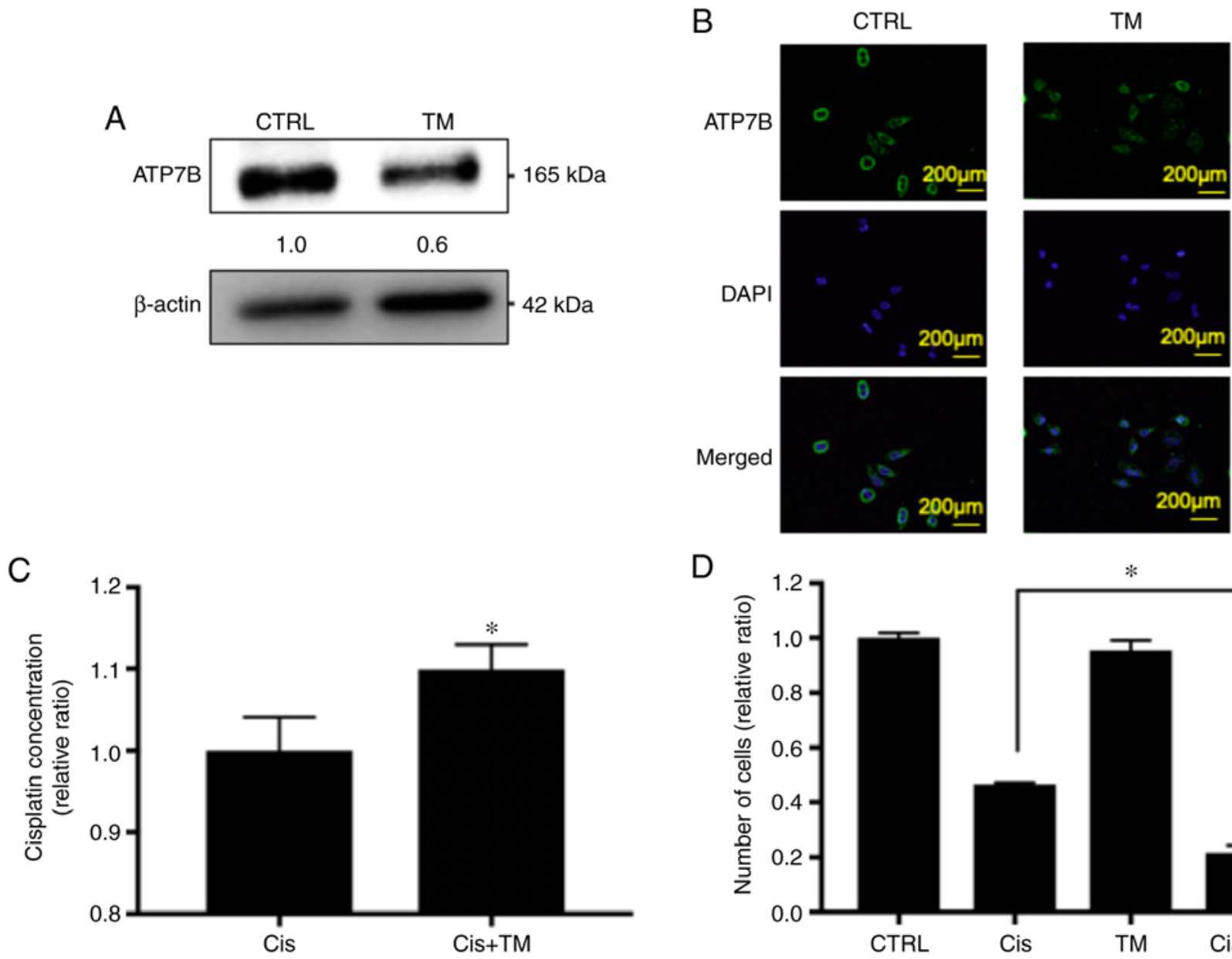

$\mathrm{D}$

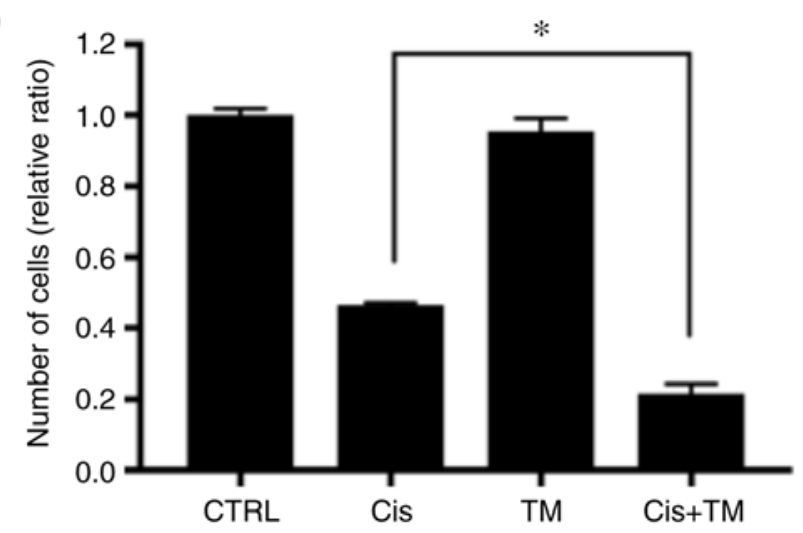

Figure 2. Effect of TM on ATP7B expression and the synergistic antitumor effect of cisplatin in HNSCC cell proliferation in vitro via cisplatin accumulation. HSC 3 cells were plated in triplicate and treated with $5 \mu \mathrm{M}$ TM for $24 \mathrm{~h}$. (A) The expression of ATP7B in control HSC-3 cells and TM-treated HSC-3 cells was analyzed based on the image blot density revealed by western blotting. (B) Immunofluorescence analysis of ATP7B and DAPI in the cells. Upper images, ATP7B (green); middle images, DAPI (blue); lower images, merged. Sections were incubated with rabbit anti-ATP7B (1:100), then with Alexa Fluor 488 anti-rabbit IgG $(1: 1,000)$ and encapsulated with DAPI. (C) The cisplatin concentration in HSC-3 cells was evaluated after 6-h cisplatin treatment with or without 24-h TM pre-incubation. (D) Antitumor and synergistic antitumor effect of TM against HSC-3 HNSCC cells. HSC-3 cells were treated with cisplatin with or without TM for $24 \mathrm{~h}$. Live cells were counted with trypan blue reagent. Data represent the relative ratio (the control is indicated as 1.0 ). ${ }^{*} \mathrm{P}<0.05$ cisplatin $+\mathrm{TM}$ group vs. the cisplatin treated group. TM, tetrathiomolybdate; ATP7B, ATPase copper transporting beta; HNSCC, head and neck squamous cell carcinoma.

$(1: 1,000)$ as a secondary antibody. Nuclei were counterstained with Fluoroshield mounting medium with DAPI (product no. ab104139; Abcam).

Statistical analysis. The data were analyzed using an unpaired Student's t-test for comparisons of two groups and by performing a one-way analysis of variance (ANOVA) and a post hoc Bonferroni or Dunnett's test for multiple group comparisons. Graph Pad Prism, ver. 7.0 (GraphPad Software, Inc., La Jolla, CA, USA). was used for all analyses. The results are expressed as the mean \pm standard deviation (SD). Probability $(\mathrm{P})$-values $<0.05$ were considered to indicate a statistically significant difference.

\section{Results}

ATP7B expression in the human HNSCC tissue. Fig. 1A provides a representative histological pattern of normal oral tissue and HNSCC tissue. ATP7B was expressed significantly higher in the HNSCC samples compared to the normal epithelium samples $(\mathrm{P}<0.0001)$ (Fig. 1B). To determine whether
HNSCC cells expressed ATP7B in vitro, western blot analysis was performed in HSC-2, HSC-3 and HSC-4 cells. As revealed in Fig. 1C, the results of the western blot analysis revealed a high expression of ATP7B in the HNSCC cells. CTR1 is a cisplatin influx transporter. The human head and neck carcinoma cell line HSC-3 markedly expressed CTR1. Thus, HSC-3 cells were used for the subsequent experiment.

TMenhances the antitumor effect of cisplatin on oral squamous cell carcinoma cells. The effect of TM on the expression of the cisplatin efflux transporter ATP7B was then assessed in HNSCC cells by western blotting, immunocytochemical analysis and Real-time PCR. First, TM was added to an HSC-3 culture medium for $24 \mathrm{~h}$, and as revealed in Figs. 2A and S1, the protein expression of ATP7B in the TM-treated HSC-3 cells was decreased by $40 \%$, while the mRNA expression of ATP7B in the TM-treated HSC-3 cells was not altered. Next, immunocytochemical analysis was performed, and the results indicated that ATP7B expression in the cell membrane was decreased by TM treatment, confirming the results of the western blotting (Fig. 2B). 
A

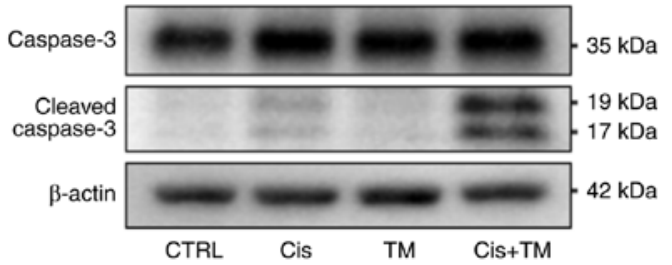

B
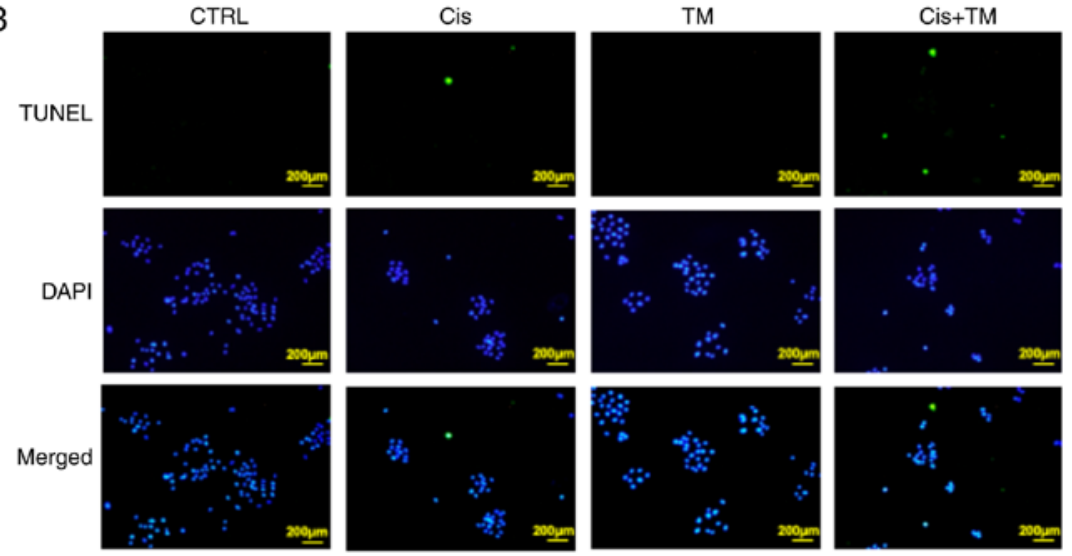

C
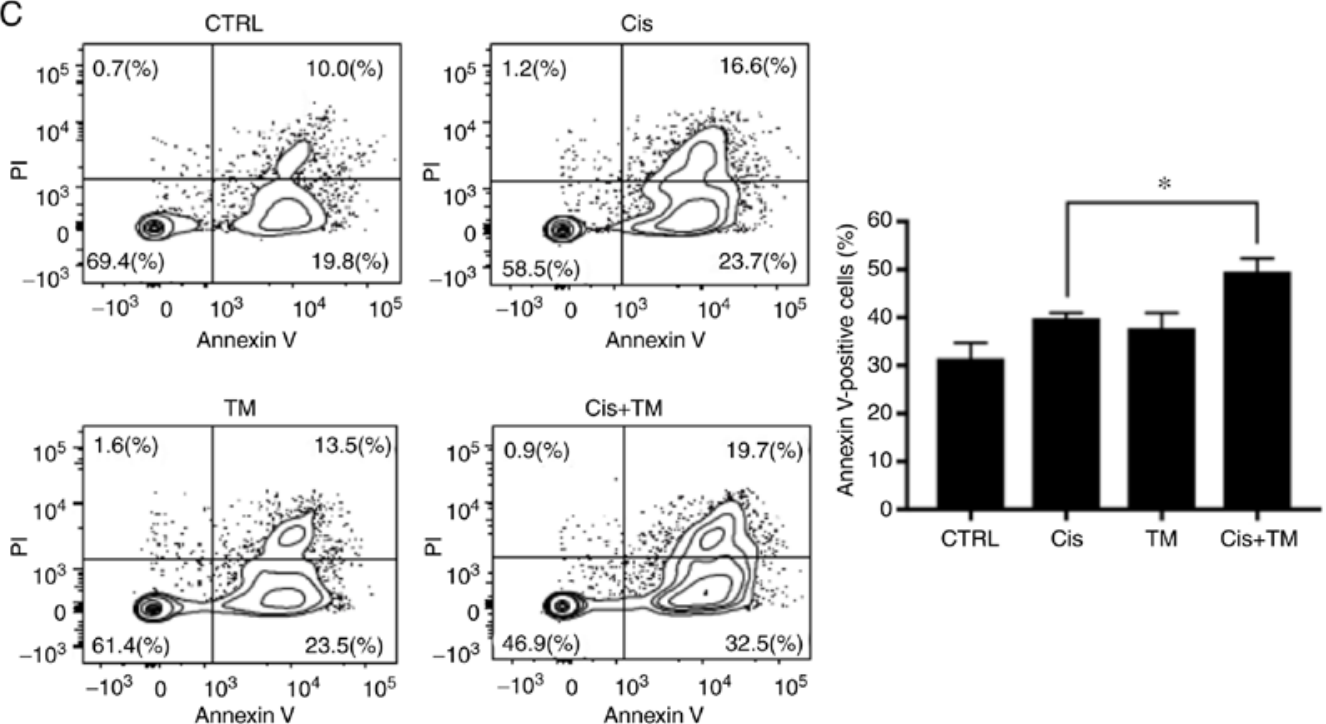

Figure 3. Apoptosis effects of TM and cisplatin on HNSCC cells grown in vitro. (A) The expression of total and cleaved caspase-3 in HSC-3 cells treated with or without cisplatin and TM. Total and cleaved caspase-3 in HSC-3 cells was evaluated based on the image blot density revealed by western blotting. (B) Immunofluorescence analysis of Tunnel and DAPI in the HSC-3 cells. Upper images, Tunnel (green); middle images, DAPI (blue), lower images, merged (C) Flow cytometric analysis: Propidium iodide (PI) and Annexin V staining of HSC-3 cells treated with cisplatin or with cisplatin+TM for 24 h. Apoptopic cells were evaluated with FACS Aria III. TM, tetrathiomolybdate; HNSCC, head and neck squamous cell carcinoma. Data are expressed as the mean \pm SD. ${ }^{*} \mathrm{P}<0.05$. Cisplatin+ TM-treated vs. cisplatin-treated cells.

Based on these data, it was hypothesized that TM may enhance the antitumor effect of cisplatin in HNSCC cells via an accumulation of cisplatin. It was therefore evaluated whether TM increased the cisplatin accumulation in the HNSCC cell lines, by performing a platinum assay. As revealed in Fig. 2C, the cisplatin concentration in the HSC-3 cells was increased by pretreatment with TM. Next, to analyze the additive antitumor effect of TM and cisplatin against HNSCC cells in vitro, a trypan blue staining assay was performed. As revealed in Fig. 2D, TM did not affect the number of viable HSC-3 cells up to $48 \mathrm{~h}$ after treatment compared with the control. Cisplatin decreased the proliferation of HSC-3 cells compared with the control group.
Notably, the TM+cisplatin dual treatment significant decreased the cell proliferation compared to the single treatment of cisplatin. The antitumor effect of cisplatin consists of inducing apoptosis by DNA cross-linking in cancer cells. The cleavage of caspase-3 is well known as an indicator of apoptosis. The effect of TM on cisplatin-induced cleavage of caspase- 3 was therefore assessed by performing a western blot analysis. As revealed in Fig. 3A, TM and cisplatin did not affect the expression of total caspase-3. Furthermore, TM did not directly induce the cleavage of caspase-3. However, TM enhanced the cisplatin-induced cleavage of caspase-3. Moreover, TM enhanced the cisplatin-induced DNA fragmentation as evaluated by fluorescence 
A

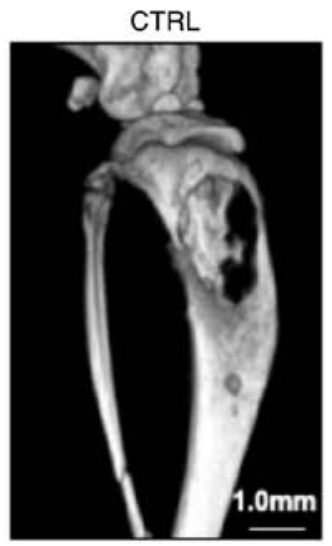

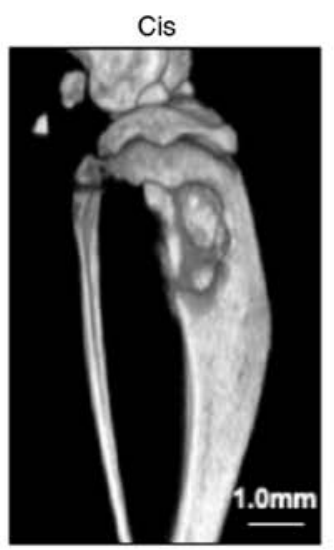
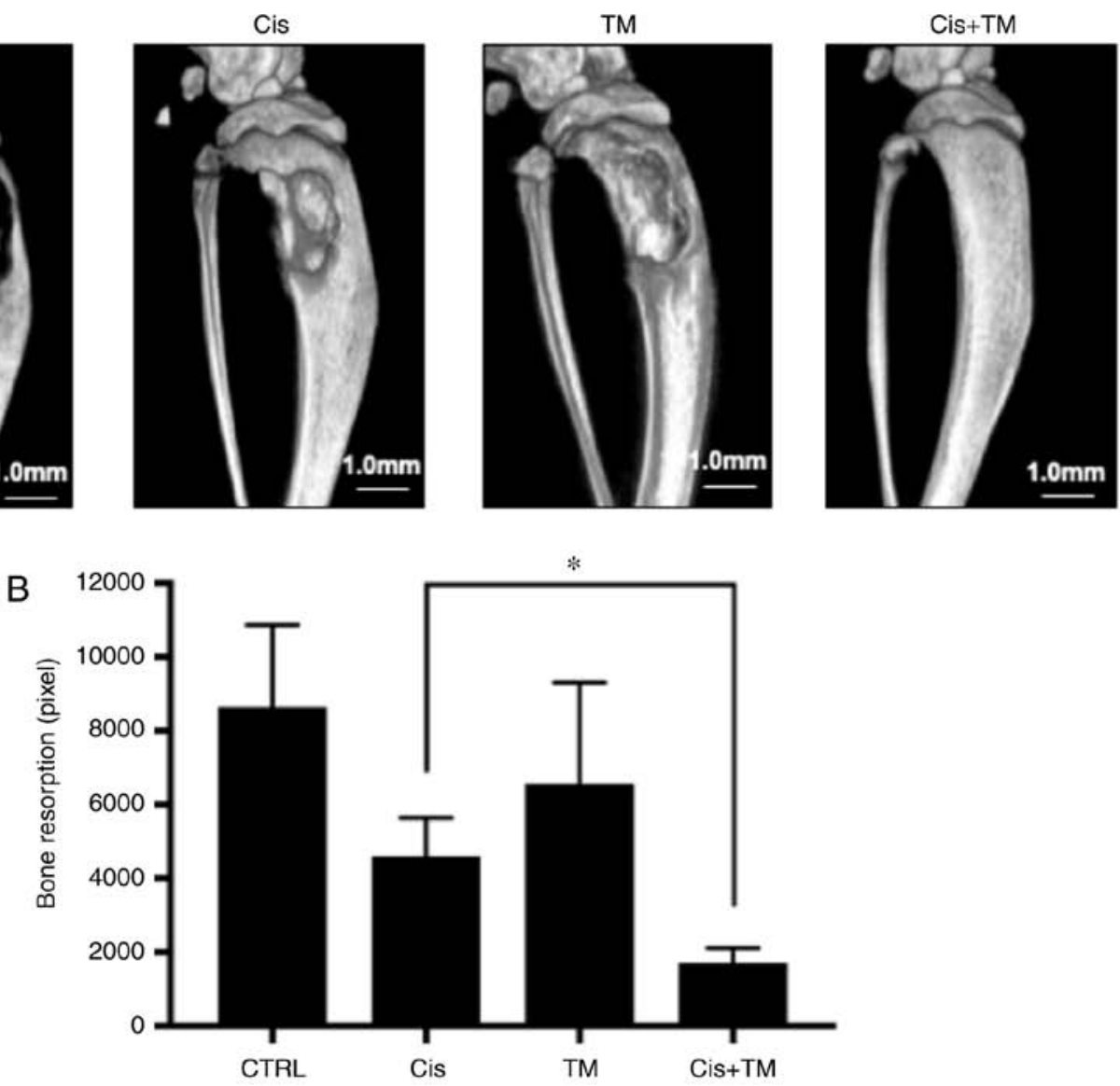

C

CTRL

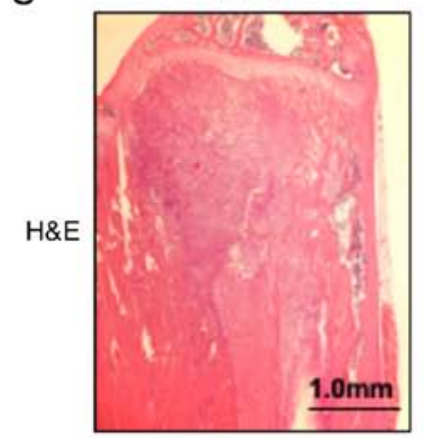

D

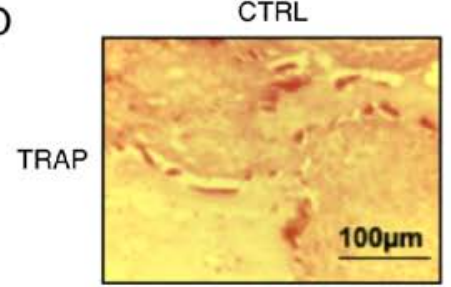

Cis

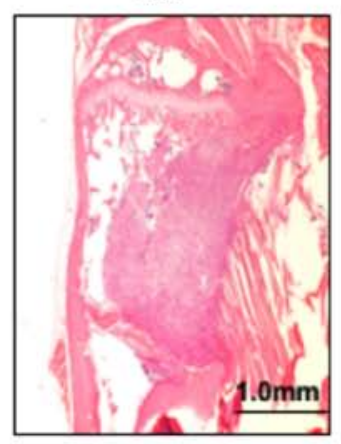

Cis

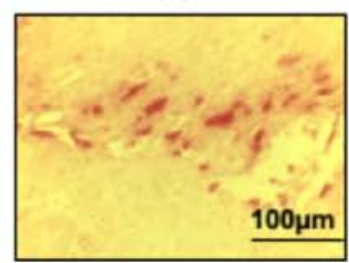

TM

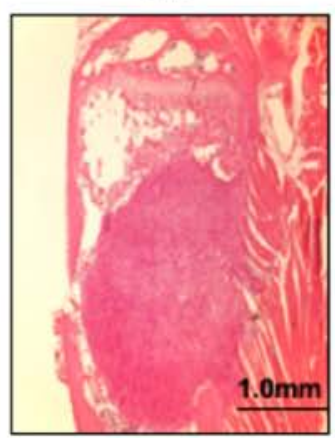

TM

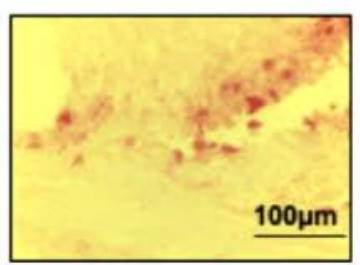

Cis + TM

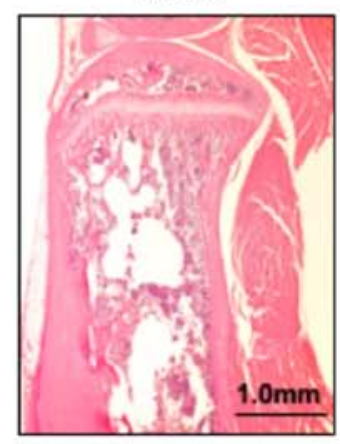

Cis+TM

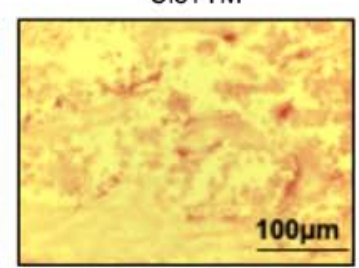

Figure 4. Effects of tetrathiomolybdate (TM) on the mouse model of cancer-associated bone destruction. (A) Representative radiographs and micro-CT of a tibia from a mouse with HSC-3 injected bone invasion after a single treatment of TM or low-dose cisplatin or a combination treatment of TM+low-dose cisplatin. (B) Bone resorption area with a soft X-ray photograph image, assessed with the LuminaVision imaging software program (Mitani Corporation). Data are expressed as the mean \pm SD. ${ }^{*} \mathrm{P}<0.05$. Cisplatin+ TM-treated vs. cisplatin-treated mice. (C) Histological and histomorphometric analysis of the bone marrow in the bone invasion mouse model. The sections of mouse tibial bone marrow were stained with hematoxylin and eosin. (D) Osteoclast visualized with TRAP stain. TM, tetrathiomolybdate; H\&E, hematoxylin and eosin; TRAP, tartrate-resistant acid phosphatase.

tunnel staining assay (Fig. 3B). Flow cytometric analysis was also performed to evaluate the effect of TM on cisplatin-induced HNSCC apoptosis. The plots of Annexin V/FITC-A vs. propidium iodide-A from the gated cells revealed the populations corresponding to viable and non-apoptotic (Annexin $\mathrm{V}^{-} \mathrm{PI}^{-}$) and (Annexin $\mathrm{V}^{+} \mathrm{PI}^{+}$, Annexin $\mathrm{V}^{+} \mathrm{PI}^{-}$) apoptotic cells. TM did not directly induce apoptosis of HSC-3 cells (control 29.8\%, TM 37.0\%). However, TM significantly enhanced the effect of 
A

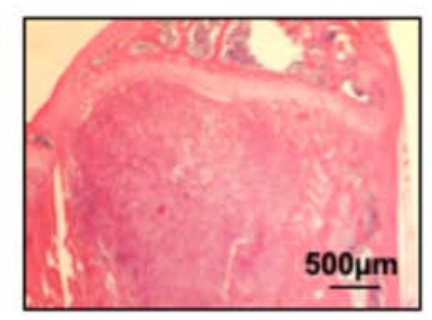

$\mathrm{H} \& \mathrm{E}$

(low magnification)

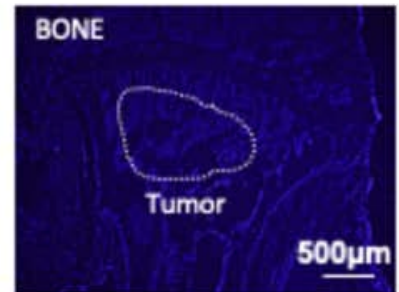

DAPI

(low magnification)
B
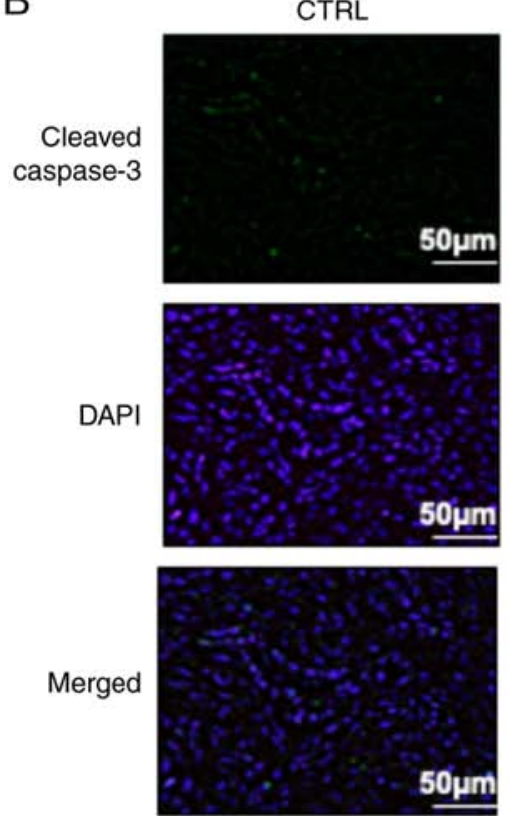
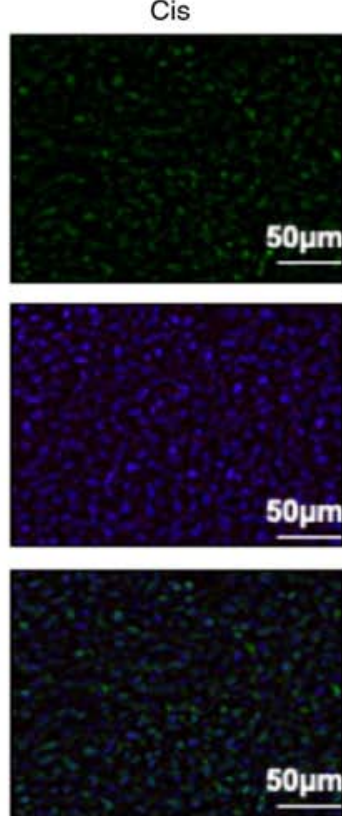

TM
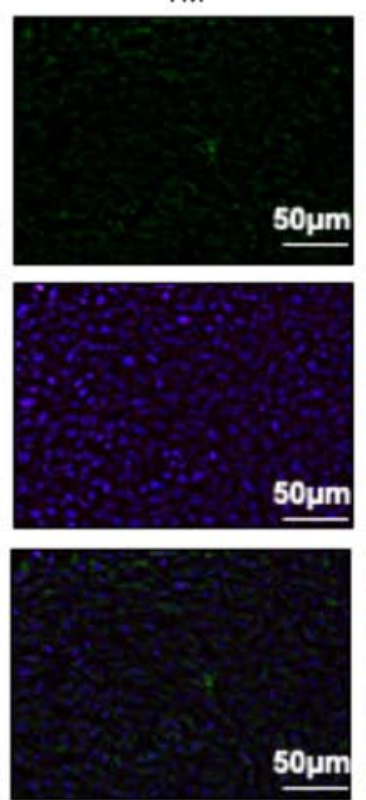

Cis+TM

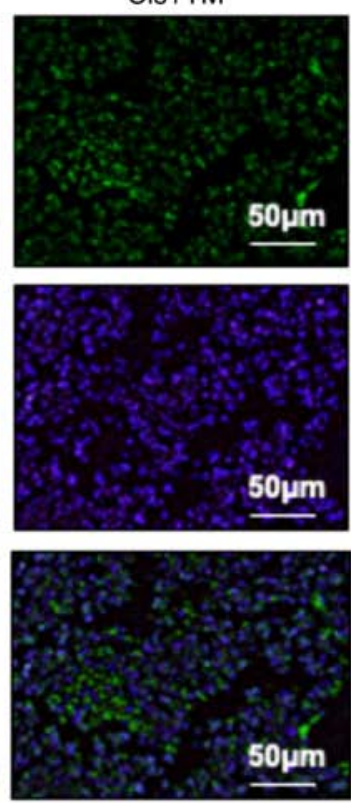

Figure 5. Immunofluorescence analysis of the tumor in the bone marrow in the mouse model of bone invasion. Representative sections of HSC-3 injected mouse tibial bone marrow stained with (A, low magnification) H\&E and DAPI; (B, green: High magnification) cleaved caspase-3 and DAPI stained with blue ( $n=6 /$ group). H\&E, hematoxylin and eosin.

cisplatin-induced apoptosis (cisplatin $40.3 \%$, cisplatin with TM $52.2 \%$ ) (Fig. 3C).

TM enhances the anticancer effect of cisplatin and bone resorption in vivo. To analyze the dual treatment effect of TM+cisplatin in vivo, an HNSCC bone invasion mouse model was established using HSC-3 cells. The mice were administered TM $(1 \mathrm{mg} / \mathrm{kg})$ and/or a low dose cisplatin $(5 \mathrm{mg} / \mathrm{kg})$ $5 \mathrm{x}$ /week beginning 7 days after the tumor inoculation, and the tumor volume was measured on day 35 . The dual treatment effect of TM+low-dose cisplatin on osteolytic bone destruction induced by oral squamous carcinoma was determined by conducting soft X-ray and micro-CT examinations. As revealed in Fig. 4A and B, the osteolytic lesions were clearly visible in the tibiae of the mice with bone invasion induced by HSC-3 cells treated with the vehicle (control) only. The use of TM or low-dose cisplatin alone tended to suppress the osteolytic bone destruction and tumor burden in the bone marrow. Notably, few destructive lesions were detected in the tibiae of the mice treated with $\mathrm{TM}+$ low-dose cisplatin. The total area of radiographic osteolytic lesions from all tibiae was significantly suppressed by the $\mathrm{TM}+$ cisplatin treatment compared to treatment with cisplatin treatment $(\mathrm{P}<0.05)$. Hematoxylin and eosin $(\mathrm{H} \& \mathrm{E})$ staining revealed tumor growth in bone marrow.
The dual treatment with $\mathrm{TM}+$ cisplatin markedly decreased the tumor burden (Fig. 4C). Morisawa et al demonstrated that TM has an anti-bone resorption effect by suppressing osteoclastogenesis via suppression of RANKL in osteoblasts (17). As revealed in Fig. 4D, treatment with TM decreased the number of tartrate-resistant acid phosphatase (TRAP)-positive osteoclasts in the bone marrow tumor invasion front. The present findings are consistent with those of Morisawa et al Imunohistochemical analysis of tumor-inoculated mouse tibia bone marrow was performed. Fig. 5A reveals a representative low magnification image of an HSC-3-inoculated mouse tibial bone marrow section stained with H\&E and DAPI. The immunohistochemical analysis revealed a marked increase in the number of cleaved caspase-3-positive tumor cells in HSC-3 tumor sections from the cisplatin-treated mice. Whereas TM alone did not increase the expression of cleaved caspase-3, the dual treatment of TM+cisplatin enhanced the expression of cleaved caspase-3 compared to the treatment with either TM or cisplatin alone (Fig. 5B). The expression of the cell growth indicator Ki-67 was also evaluated in low-dose cisplatin-treated mice. Although TM did not affect Ki-67 expression, the $\mathrm{TM}+$ cisplatin dual treatment significantly decreased the expression of Ki-67 (Fig. 6A). TM treatment did not affect the expression of IL- 6 which is an important 
A
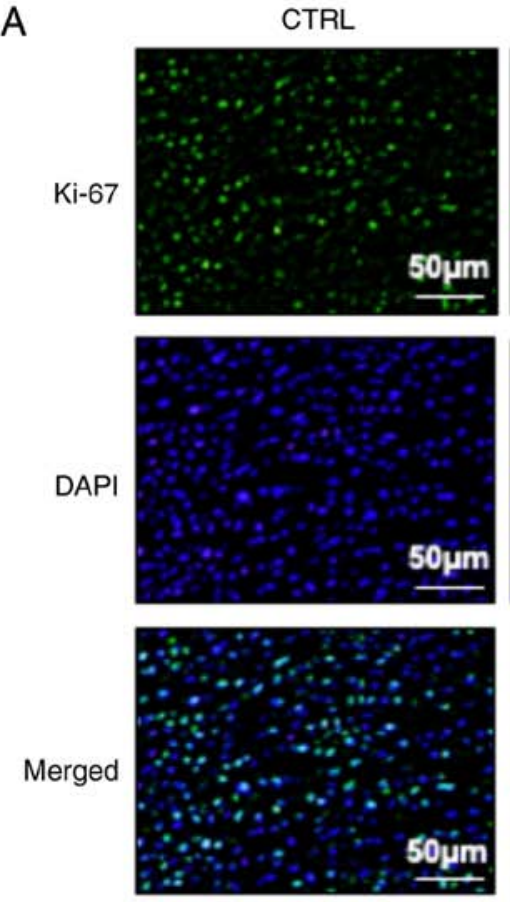

B
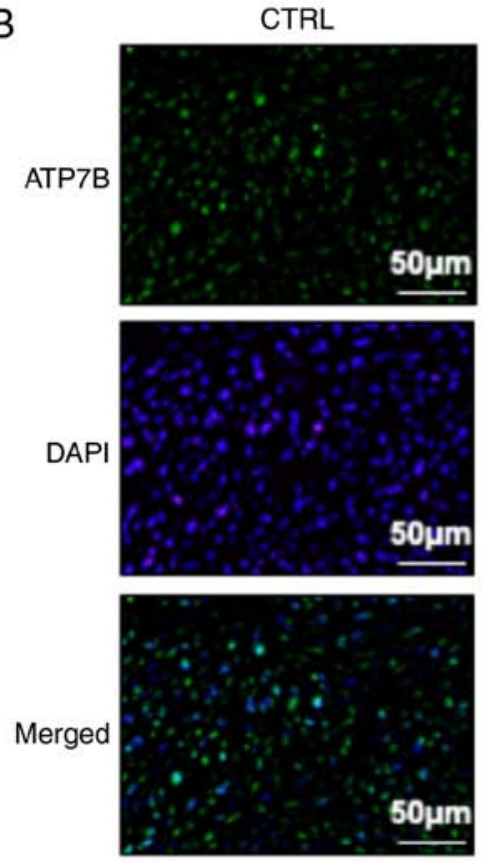

Cis
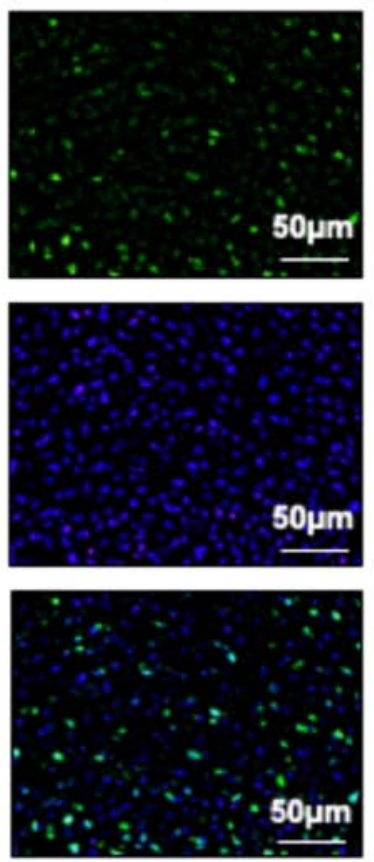

Cis
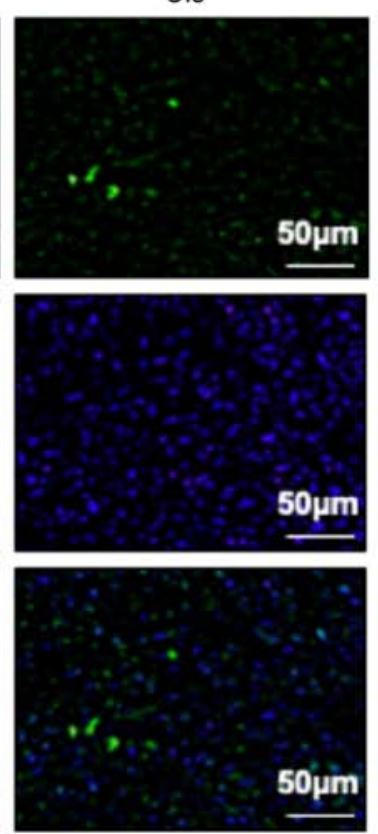

TM
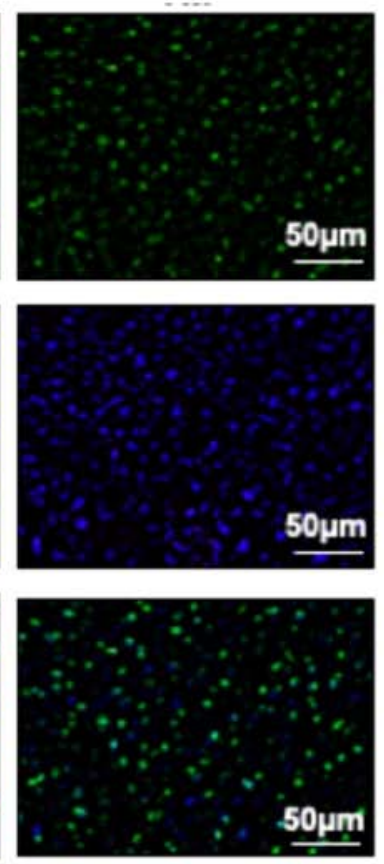

TM
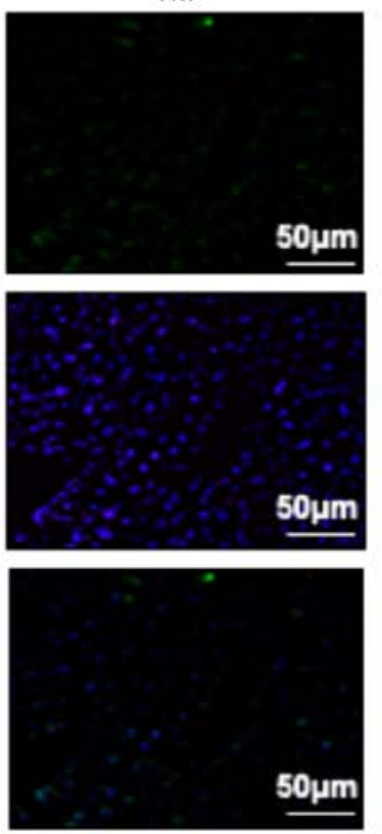

Cis + TM
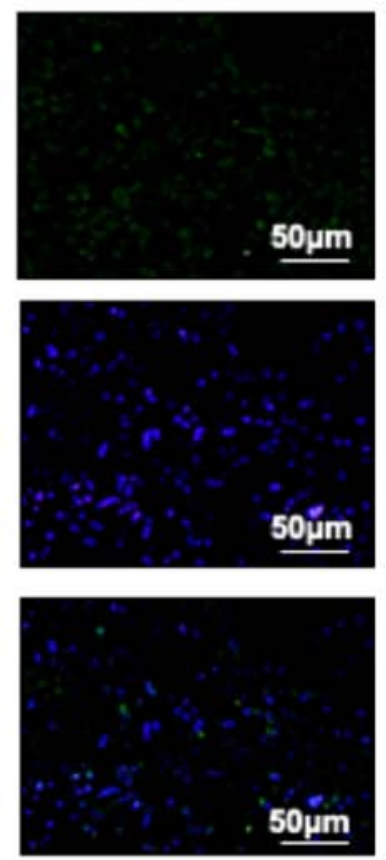

Cis+TM
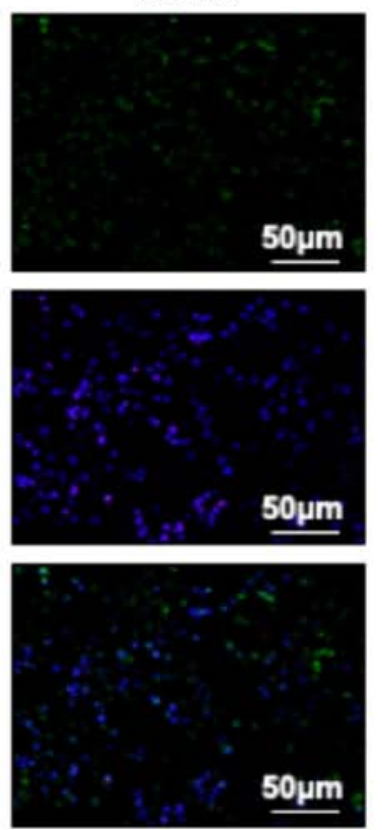

Figure 6. Immunofluorescence analysis of the tumor in the bone marrow in the mouse model of bone invasion. (A, green: High magnification) KI-67, (B, green: High magnification) ATP7B and DAPI stained with blue ( $\mathrm{n}=6 /$ group). ATP7B, ATPase copper transporting beta.

bone remodeling factor (Fig. S2). Collectively these results indicated that TM enhanced the antitumor effect of cisplatin. Finally, immunohistochemical evaluation was conducted to determine the effect of TM on the in vivo expression of the copper transporter ATP7B. Notably, TM decreased the expression of ATP7B compared with the control group. These data indicated that TM enhanced the antitumor effect of cisplatin via an accumulation of cisplatin in the cancer cells (Fig. 6B).

TM overcomes cisplatin resistance. The accumulation of cisplatin is decreased in most of the available cisplatin-resistant cell lines, and an active efflux system for cisplatin exists in some of these cell lines (4-12). The results of the present investigations indicated that TM treatment may overcome cisplatin resistance. Mese et al established the cisplatin-resistant human skin squamous cell carcinoma cell line A431 (18). This cell line (A431-CDDP-R) was used to evaluate the ability of TM treatment to overcome cisplatin resistance. Notably, the parental A431 cells only slightly expressed ATP7B. In contrast, the A431/CDDP-R cells strongly expressed ATP7B (Fig. 7A). To assess the ability of TM treatment to overcome cisplatin resistance in A431/CDDP-R cells, the cells were pretreated with TM for $24 \mathrm{~h}$. The cells were then treated with cisplatin for $24 \mathrm{~h}$. A western blot analysis revealed that the TM treatment 
A

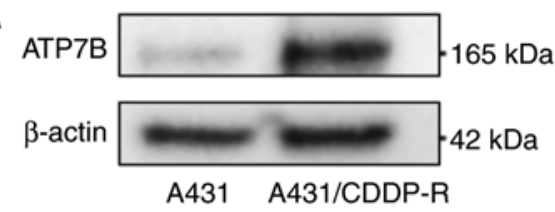

B
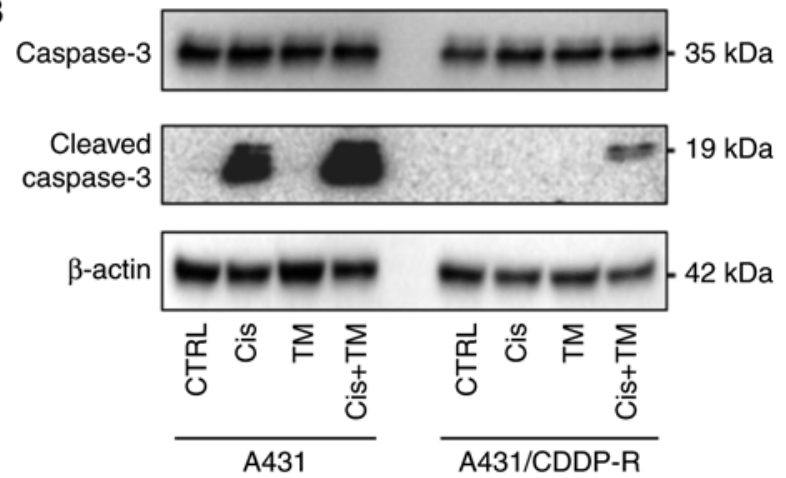

Figure 7. The role of ATP7B in cisplatin-resistant cancer cells. (A) The expression of ATP7B in the parental and cisplatin-resistant A431 cancer cells (A431/CDDP-R) was evaluated by a western blot analysis. (B) A431 and A431/CDDP-R cells were incubated with cisplatin with or without TM. Cleaved caspase- 3 was evaluated with western blotting. TM, tetrathiomolybdate; ATP7B, ATPase copper transporting beta; CDDP, cis-dichloro-diamine-platinum-resistant.

slightly enhanced the cisplatin-induced cleaved caspase-3 expression in parental A431 cells. Treatment with cisplatin alone did not induce cell apoptosis in A431/CDDP-R cells. Notably, pretreatment with TM strongly enhanced the apoptosis effect of cisplatin in A431/CDDP-R cells (Fig. 7B).

\section{Discussion}

Copper chelators have been reported to inhibit cancer cell growth in vitro and in vivo (21-23). Copper metabolism is critical for cell proliferation, and it is strictly regulated by the copper transporters Crt1, ATP7A, and ATP7B. ATP7B is expressed in mitochondria and excretes copper from the cytoplasm to the extracellular space (15). Cisplatin is the most frequently used platinum-based alkylating agent for several cancers. Cisplatin binds to DNA and causes intra-strand crosslinking, leading to apoptosis (9). Cisplatin is transported into cancer cells via the copper transporter Ctr1 (24). Some clinical studies have indicated that the CTR1 expression in tumors was correlated with the therapeutic efficacy of platinum drugs $(25,26)$. It was also indicated that high extracellular copper levels suppressed CTR1 expression, thereby preventing excess copper influx (27). However, the role of ATP7B in cancer cells remains unknown. The present findings are the first, to the best of our knowledge, to demonstrate that the copper chelator TM enhanced the efficacy of cisplatin in HNSCC via a decrease in the expression of ATP7B. However, the detailed mechanism underlying the decrease in ATP7B expression remains unclear. A recent study indicated that TM induces dimerization of ATP7B, leading to loss of the copper efflux transporter function (28). Furthermore, the copper chelator decreased the expression of ATP7B in liver cancer cell lines (14). This mechanism may be associated with our results. The present experiments revealed that tissues from patients with HNSCC expressed high levels of ATP7B compared to normal oral tissue (Fig. 1). The expression of ATP7B in several HNSCC cell lines was thus evaluated. In addition, since it has been hypothesized that the copper concentration in the extracellular space mediates the expression of copper transporter proteins (26), the effect of the copper chelator TM was investigated on the expression of the copper efflux transporter ATP7B in HNSCC cell lines. The present findings are the first to demonstrate that the chelation of copper ions by TM inhibited the ATP7B expression in HSC-3 HNSCC cells. Thus, it was surmised that this effect was due to the maintenance of the copper metabolism of cancer cells.

Based on our aforementioned results, it was hypothesized that TM inhibited the cisplatin efflux from cancer cells. Then, it was evaluated whether TM accelerates the apoptotic effect of cisplatin, and it was observed that TM increased the intracellular cisplatin concentration in HNSCC, resulting in an inhibition of the cell proliferation in vitro. These results indicate that the copper efflux transporter was a critical mediator of cisplatin efficacy against cancer cells. The present experiments also revealed that TM did not affect the proliferation of HSC-3 HNSCC cells. We reported previously that TM did not inhibit the growth of fibroblasts, osteocytes, osteoblasts, or T cells, which is consistent with other studies $(17,29)$. We also reported the molecular mechanism of TM in osteoclastogenesis in bone marrow (17). TM decreased the activation of LOX and the RANKL expression in osteoblasts, resulting in a decrease in osteoclast formation in the HNSCC-induced bone resorption area.

HNSCC frequently invades facial bone, which is a source of growth factors for cancer cells (30). To assess the clinical synergistic effects of copper-lowering agents and platinum agents, TM and low-dose cisplatin was administered in a mouse model of bone-destructive HNSCC, and the results indicated that treatment with either low-dose cisplatin or TM alone partially reduced the tumor growth in bone (Fig. 4A-C). Notably, the combination treatment of cisplatin+TM significantly decreased the tumor growth and bone resorption, $\mathrm{Ki}-67$ expression and cleaved caspase- 3 expression compared to the single treatment with either agent (Figs. 5 and 6). This additive effect was due to the suppression of HNSCC cell proliferation via an accumulation of cisplatin in HNSCC cells and to osteoclast formation by TM (Fig. 4D).

In a clinical setting, the efficacy of cisplatin-based chemotherapy against cancers is limited by the occurrence of innate and acquired drug resistance, and a recent study revealed that the mechanism of cisplatin resistance is based on the copper transporter regulation in cancer cells (31). In the present study, the administration of cisplatin increased the level of the cisplatin efflux transporter ATP7B. We hypothesized that cancer cells increase the expression of ATP7B to escape from cisplatin accumulation and cell death. To evaluate the mechanism of the function of ATP7B in cisplatin resistance, (epidermoid carcinoma) A431 cells were used. Mese et al established cisplatin-resistant A431 cells $(18,19)$. The expression of ATP7B in parental A431 and cisplatin-resistant A431 (A431 CDDP-R) cells was evaluated, and notably, the ATP7B expression in the A431CDDP-R cells was markedly increased compared to the expression in the parental A431 cells. It was speculated that the cisplatin-resistant A431 cells discharged cisplatin via an increase in ATP7B expression. The present experiments demonstrated that TM enhanced the caspase- 3 cleavage by cisplatin. These 
results indicated that the mechanism of cisplatin resistance in A431 CDDP-R cells is attributable to an acceleration of the efflux of cisplatin from cells. However, the present data revealed one possibility that ATP7B expression is associated to cisplatin resistance. ATP7B knockdown or a knock-out HNSCC cell line must be established to demonstrate this hypothesis in a future experiment.

In summary, to the best of our knowledge, the present study is the first to reveal that a copper-lowering agent could be an adjuvant to therapy with platinum agents against HNSCC, and the present findings strongly indicate that TM with cisplatin may be an effective approach for treating advanced HNSCC. A clinical study conducted at the MD Anderson Cancer Center revealed that copper-lowering agents have the potential to overcome cisplatin resistance in ovarian cancer patients by regulating the copper transporter hCtrl (32). The present in vitro and in vivo results strongly support the notion that copper-lowering agents including TM could be a clinically effective breakthrough for overcoming cisplatin resistance. A copper-lowering agent could be an adjuvant to therapy with platinum agents against HNSCC, and the present findings strongly suggest that TM with cisplatin may be an effective approach to treat advanced HNSCC.

\section{Acknowledgements}

Not applicable.

\section{Funding}

The present research was funded by a Grant-in-Aid for Young Scientists (JSPS KAKENHI grant no. 18K17225) to TO and the Grant-in-Aid for Scientific Research (B) (JSPS KAKENHI grant no. 17H04405) to AS from the Ministry of Education, Culture, Sports, Science, and Technology of Japan.

\section{Availability of data and materials}

The datasets used and analyzed during the current study are available from the corresponding author on reasonable request.

\section{Author's contributions}

TO conceived and designed the experiments. SR, TO, TS and KH performed the experiments. TO, SR, KK, SI, NMMH, AS analyzed and interpreted the data. SR, TO, KH, SI, YK, KA, NTTH performed the data acquisition. TO wrote the paper. KK, TS, SI, NMMH and AS revised/reviewed the manuscript. All authors read and approved the final manuscript.

\section{Ethics approval and consent to participate}

All of the animal experimental protocols were approved by the Ethics Review Committee for Animal Experimentation of the Okayama University Graduate School of Medicine and Dentistry (approval no. OKU-2018663).

\section{Patient consent for publication}

Not applicable.

\section{Competing interests}

The authors declare that they have no competing interests.

\section{References}

1. Global Burden of Disease Cancer Collaboration; Fitzmaurice C, Akinyemiju TF, Al Lami FH, Alam T, Alizadeh-Navaei R, Allen C, Alsharif U, Alvis-Guzman N, Amini E, et al: Global, Regional, and national cancer incidence, mortality, years of life lost, years lived with disability, and disability-adjusted life-years for 29 cancer groups, 1990 to 2016: A Systematic analysis for the global burden of disease study. JAMA Oncol 4: 1553-1568, 2018.

2. Argiris A, Karamouzis MV, Raben D and Ferris RL: Head and neck cancer. Lancet 371: 1695-1709, 2008.

3. Carvalho AL, Nishimoto IN, Califano JA and Kowalski LP: Trends in incidence and prognosis for head and neck cancer in the United States: A site-specific analysis of the SEER database. Int J Cancer 114: 806-816, 2005.

4. Guan J, Li Q, Zhang Y, Xiao N, Chen M, Zhang Y, Li L and Chen L: A meta-analysis comparing cisplatin-based to carboplatin-based chemotherapy in moderate to advanced squamous cell carcinoma of head and neck (SCCHN). Oncotarget 7: 7110-7119, 2016.

5. Nagasaka M, Zaki M, Issa M, Kim H, Abrams J and Sukari A: Definitive chemoradiotherapy with carboplatin for squamous cell carcinoma of the head and neck. Laryngoscope 127: 2260-2264, 2017.

6. Gao Y and Liu D: The roles of excision repair cross-complementation group 1 in objective response after cisplatin-based concurrent chemoradiotherapy and survival in head and neck cancers: A systematic review and meta-analysis. Oral Oncol 51: 570-577, 2015.

7. Dasari S and Tchounwou PB: Cisplatin in cancer therapy: Molecular mechanisms of action. Eur J Pharmacol 740: 364-378, 2014.

8. Mehmood RK: Review of Cisplatin and oxaliplatin in current immunogenic and monoclonal antibody treatments. Oncol Rev 8: $256,2014$.

9. Chvalova K, Brabec V and Kasparkova J: Mechanism of the formation of DNA-protein cross-links by antitumor cisplatin. Nucleic Acids Res 35: 1812-1821, 2007.

10. Chung CH, Lee JW, Slebos RJ, Howard JD, Perez J, Kang H, Fertig EJ, Considine M, Gilbert J, Murphy BA, et al: A 3'-UTR KRAS-variant is associated with cisplatin resistance in patients with recurrent and/or metastatic head and neck squamous cell carcinoma. Ann Oncol 25: 2230-2236, 2014.

11. Damia G and Broggini M: Platinum resistance in ovarian cancer: Role of DNA repair. Cancers (Basel) 11: E119, 2019.

12. Fadejeva I, Olschewski H and Hrzenjak A: MicroRNAs as regulators of cisplatin-resistance in non-small cell lung carcinomas. Oncotarget 8: 115754-115773, 2017.

13. Lambert IH and Sorensen BH: Facilitating the cellular accumulation of Pt-based chemotherapeutic drugs. Int J Mol Sci 19: pii: E2249, 2018.

14. Leonhardt K, Gebhardt R, Mossner J, Lutsenko S and Huster D: Functional interactions of Cu-ATPase ATP7B with cisplatin and the role of ATP7B in the resistance of cells to the drug. J Biol Chem 284: 7793-7802, 2009.

15. Inesi G: Molecular features of copper binding proteins involved in copper homeostasis. IUBMB Life 69: 211-217, 2017.

16. Roberts EA: Update on the diagnosis and management of wilson disease. Curr Gastroenterol Rep 20: 56, 2018.

17. Morisawa A, Okui T, Shimo T, Ibaragi S, Okusha Y, Ono M, Nguyen TTH, Hassan NMM and Sasaki A: Ammonium tetrathiomolybdate enhances the antitumor effects of cetuximab via the suppression of osteoclastogenesis in head and neck squamous carcinoma. Int J Oncol 52: 989-999, 2018.

18. Mese H, Sasaki A, Alcalde RE, Nakayama S and Matsumura T: Establishment and characterization of cisplatin-resistant human epidermoid carcinoma cell line, A431 cell. Chemotherapy 44: 414-420, 1998.

19. Mese H, Sasaki A, Nakayama S, Alcalde RE and Matsumura T: The role of caspase family protease, caspase- 3 on cisplatin-induced apoptosis in cisplatin-resistant A431 cell line. Cancer Chemother Pharmacol 46: 241-245, 2000. 
20. Livak KJ and Schmittgen TD: Analysis of relative gene expression data using real-time quantitative PCR and the 2(-Delta Delta C(T)) method. Methods 25: 402-408, 2001.

21. Chan N, Willis A, Kornhauser N, Ward MM, Lee SB, Nackos E, Seo BR, Chuang E, Cigler T, Moore A, et al: Influencing the tumor microenvironment: A phase II study of copper depletion using tetrathiomolybdate in patients with breast cancer at high risk for recurrence and in preclinical models of lung metastases. Clin Cancer Res 23: 666-676, 2017.

22. Chisholm CL, Wang H, Wong AH, Vazquez-Ortiz G, Chen W, $\mathrm{Xu} \mathrm{X}$ and Deng CX: Ammonium tetrathiomolybdate treatment targets the copper transporter ATP7A and enhances sensitivity of breast cancer to cisplatin. Oncotarget 7: 84439-84452, 2016.

23. Park SJ, Kim MJ, Kim YK, Kim SM, Park JY and Myoung H: Combined cetuximab and genistein treatment shows additive anti-cancer effect on oral squamous cell carcinoma. Cancer Lett 292: 54-63, 2010

24. Ishida S, Lee J, Thiele DJ and Herskowitz I: Uptake of the anticancer drug cisplatin mediated by the copper transporter Ctr1 in yeast and mammals. Proc Natl Acad Sci USA 99: 14298-14302, 2002.

25. Xu X, Duan L, Zhou B, Ma R, Zhou H and Liu Z: Genetic polymorphism of copper transporter protein 1 is related to platinum resistance in Chinese non-small cell lung carcinoma patients. Clin Exp Pharmacol Physiol 39: 786-792, 2012.

26. Kim ES, Tang X, Peterson DR, Kilari D, Chow CW, Fujimoto J, Kalhor N, Swisher SG, Stewart DJ, Wistuba II and Siddik ZH: Copper transporter CTR1 expression and tissue platinum concentration in non-small cell lung cancer. Lung Cancer 85: 88-93, 2014.
27. Molloy SA and Kaplan JH: Copper-dependent recycling of hCTR1, the human high affinity copper transporter. J Biol Chem 284: 29704-29713, 2009.

28. Fang T, Chen W, Sheng Y, Yuan S, Tang Q, Li G, Huang G, Su J, Zhang X, Zang J and Liu Y: Tetrathiomolybdate induces dimerization of the metal-binding domain of ATPase and inhibits platination of the protein. Nat Commun 10: 186, 2019.

29. Kim KK, Han A, Yano N, Ribeiro JR, Lokich E, Singh RK and Moore RG: Tetrathiomolybdate mediates cisplatin-induced p38 signaling and EGFR degradation and enhances response to cisplatin therapy in gynecologic cancers. Sci Rep 5: 15911, 2015.

30. Okui T, Shimo T, Fukazawa T, Kurio N, Hassan NM, Honami T, Takaoka M, Naomoto Y and Sasaki A: Antitumor effect of temsirolimus against oral squamous cell carcinoma associated with bone destruction. Mol Cancer Ther 9: 2960-2969, 2010.

31. Kilari D, Guancial E and Kim ES: Role of copper transporters in platinum resistance. World J Clin Oncol 7: 106-113, 2016.

32. Fu S, Naing A, Fu C, Kuo MT and Kurzrock R: Overcoming platinum resistance through the use of a copper-lowering agent. Mol Cancer Ther 11: 1221-1225, 2012.

This work is licensed under a Creative Commons Attribution-NonCommercial-NoDerivatives 4.0 International (CC BY-NC-ND 4.0) License. 